\title{
International School Principals: routes to headship and key challenges of their role Lucy Bailey
}

\section{Mark T Gibson}

\section{Abstract}

Although there is an extensive literature across a range of national contexts concerning the evolving role of the school leader, little has been written about the rapidly expanding world of international school leadership. This paper focuses on the top tier of leadership of international schools by drawing on semi-structured interviews with 12 school principals in Malaysia, during which they reflected on the nature of their job and the routes they had taken to headship. It is argued that although the overwhelming majority had taken a school leadership qualification and found elements helpful, they felt that it did not adequately prepare them for their role. Several ways in which international school leadership differs significantly from educational school leadership in other contexts are identified, with principals needing to pay attention to loneliness, transience, cultural differences, governance, business elements, and managing school composition. By identifying key challenges faced by international heads, and by charting the paths that individuals take towards headship, this article seeks to understand the nature of senior leadership in international schools.

\section{Introduction}

There is now an extensive literature on the preparation that school leaders require for their positions in different national contexts (Bush, 2018). However, very little has been written about how international school leaders are prepared for their roles, this may be because insufficient is understood about the nature of international school headship, and how this differs from school leadership in national settings. This paper will address this research gap by examining the nature of headship in international schools, and the routes that leaders take towards senior leadership of international schools. These issues are addressed through analysis of semi-structured interviews with 12 principals of international schools in Malaysia 
which were conducted in 2018. Recognising that the titles given to different levels of school leadership vary widely across international schools, it should be clarified that for the purposes of this article, 'principals' and 'leaders' only refers to the top tier of leadership within the school. In Malaysia, frequently International schools are through-schools that educate children from pre-school to 18 years of age. The schools are often split into smaller schools or divisions by age and the leaders of these sections are mainly titled 'Head of School', whilst the position that is in charge of these staff and the whole school, is predominately called a Principal.

The definition and even concept, of an international school is contested. Both Hayden (2011) and James \& Shepperd (2014) discuss the differences and historical changes that have occurred over the last fifty years. In Malaysia, international schools, are generally fee paying schools offering a foreign curriculum with the method of instruction being a foreign language. They are often staffed, certainly at senior level, by foreign nationals. With the number of international schools increasing by almost 40\% between 2012 and 2018 globally, and with projections that the number of students in international schools will reach 7 million by 2023 (ISC Research, 2019), understanding the world of international schooling is as significant to global education as understanding the education system of a medium sized country like England (Bunnell, Fertig, \& James, 2016). The nature of international schools has changed globally. Previously they predominately served the children of expatriate families, whilst now they contain a higher proportion of host nation children; there has been an increase of the number of schools within the sector that serve mainly affluent host country nationals (Hayden, 2011). This results in Bunnell et al. (2016) asking, 'what is international about an international school?' Although the increasing growth and diversity globally has created a more complicated landscape (Bunnell, Fertig, \& James, 2017), there are institutions that are predominantly 'international' international schools and others that are 'local' international schools. Malaysia reflects these global changes. These two groups, the internationally mobile global elite (Gardner-McTaggart, 2016) and the upwardly mobile host national create international schooling that offers 'social and cultural reproduction for the globalising and cosmopolitan privileged' (Gardner-McTaggart, 2018 p.149). 
Little is known about how people become senior leaders of international schools. There are leadership programmes that have been devised specifically for these institutions. For example, the Principals' Training Center was developed specifically to meet the professional development needs of leaders in international schools, with standards for international school leaders, that state, amongst other things, that they should be fostering internationalmindedness and modelling 'the skills and attitudes of a global citizen' (PTC, 2018). In addition, the International Baccalaureate Organisation has recognised certain universities that offer an IB certificate in leadership practice or an IB advanced certificate in leadership research. We are not aware of any academic research that systematically reviews such programmes; consequently, the theoretical and empirical basis for these systems of principal accreditation remains unclear. It is not clear to what extent these are systematically used as part of a route towards senior leadership, nor to what extent they prepare these leaders for the central components of leading an international school, which may be wide ranging and context specific.

The purpose of the paper is to discuss the range of challenges that international school leaders face in one situ, Malaysia, and locate this in the context of their routes to senior leadership.

\section{Literature Review}

Historically, most attention has been paid to educational leadership in Western contexts, and it has been assumed that this scholarship can be transferred unproblematically to nonWestern contexts - such as Asian systems of education or to international schools. For example, The International Successful School Leadership Project (ISSLP) has, since the start of this century, compared leadership practices across successful schools in Australia, Canada, China, Denmark, England, Norway and Sweden (Gurr, 2015) - but it is notable that this is a predominantly Western group of countries. There are some researchers who might question whether that matters - Leithwood et al (2006) argue that there are common practices shared by effective leaders across all contexts - namely, building vision and setting directions; understanding and developing people; redesigning the organisation; and 
managing the teaching and learning programme. They argue that whilst leaders need to be responsive to contexts, these practices for success are almost invariably the same.

However, there is a growing body of evidence that demonstrates that leadership is culturally embedded. As long ago as the 1970s, Geert Hofstede analysed cross-cultural data on attitudes to leadership to identify four (later, six) dimensions of difference between cultures - power distance, individualism/ collectivism, uncertainty avoidance, masculinity/ femininity, long- versus short-term orientation, and indulgence/ restraint (Hofstede, 2011). The GLOBE study at the start of this century demonstrated how these differences directly impact on the conceptualisation of effective leadership in different cultural settings (Scandura \& Dorfman, 2004), suggesting that whilst there are some leadership characteristics that are seen as universally valuable (e.g. inspiring) or universally rejected (e.g. irritability), beyond that there are distinct clusters of countries in which leadership is seen as having specific characteristics.

These insights into the cultural construction of leadership remain under-discussed in educational circles, although in recent years researchers have started to explore the implications for school leadership; for example, Hallinger \& Chen (2010) review the research into educational leadership and management that has been undertaken in Asia, and conclude that there is a lack of quality research into the topic in non-Western contexts, with uneven development of scholarship across the continent. There has also been some examination of how school leadership has changed over time as cultures evolve. For instance, Crow (2001) looks at how the role of the school leader has changed in the twentyfirst century, positing that how we conceptualise school leadership is rooted in the industrial revolution and the need to standardise production and establish routines. By contrast, in the twenty-first century we require leaders that are more dynamic, flexible and creative, and who can cope with organisational complexity and diverse individuals.

Despite this growing awareness that leadership roles are context-dependent, there are few empirical studies of educational leadership in the international school arena (Calnin et al, 2018). Although Calnin et al (2018) provide an explanation of the seven leadership intelligences identified by the IBO in their leadership intelligence programme that draws on 
a wide range of leadership theory and data, they include no empirical data collected from school leaders themselves. Yet, these schools are typically characterised by cultural diversity and transnational influences, which problematises the application of Western scholarship for the reasons discussed above. Gardner-McTaggart (2018) draws attention to the diversity of the sector, nevertheless identifying some common challenges faced by international school leaders: firstly, there is often high turnover and transience of leaders in international schools; secondly, many schools experience rapid growth (or deflation), which creates specific leadership challenges; finally, staff are also more transient, and are more willing to leave if unhappy with decisions made by the people at the top of the organisation. Other researchers have also emphasised transience as a key feature of international schools (Blandford \& Shaw, 2001; Benson, 2011), with Benson (2011) citing data that international school leaders enjoy an average tenure of only 3.7 years. Blandford \& Shaw (2001) identify several additional challenges that are specific to international school leadership, including high but varied parental expectations, uncertain procedures for governance, and dual pressures from being subject to both national (in-country) procedures and expectations as well as meeting international expectations for processes and curriculum (see also Keller, 2015). There seems to be a larger range of governance models and procedures in international schools than in national schools; as Hayden \& Thomas (2008) point out, in most national systems there are common systems and assumptions related to governance, whereas these are lacking in international schools. Although principals may appear to have more autonomy over educational matters in the school, for example, with greater curricula freedom than in most national contexts, there may well be greater accountability in marketdriven demands such as student enrolment numbers (James \& Sheppard, 2014). Lee, Hallinger \& Walker (2011) offer evidence that parents may expect exam assessments, whereas some international curricula place an emphasis on teacher assessments. In summary, there is insufficient data available to elucidate the nature of the international school principal's role across different curricula, and to substantiate some of the claims made by these researchers about the specific challenges facing international school leaders.

With this paucity of empirical data concerning international school leaders, how then can we begin to conceptualise how international school leaders are best prepared for their role? Examining national systems of leadership preparation provides the best starting point, and 
demonstrates that international models of principal preparation vary hugely. In England and Wales, a requirement that all new heads should already have completed the National Professional Qualification for Headship was introduced in 2004, but dropped in 2012 (Bush, 2016). Harris, Jones \& Adams (2016) examine leadership preparation programmes in seven different countries, noting the limited success that systems importing a version of the English leadership qualification have had because of its cultural irrelevance to their system. Bush (2018) argues that although in many places promotion to principalship remains dependent simply on a teaching qualification and teaching experience, the job of being a principal is one that requires specific preparation. This, then, raises the question of whether international school heads are best prepared by national qualifications or by a system of leadership preparation devised for international schools specifically. A deeper understanding of both the role itself and the routes that individuals take to senior leadership is a necessary precursor to investigating leadership preparation itself.

A number of authors have examined the complex process of socialisation into the role of a school principal, with formal leadership preparation now usually one part of this process. Crow (2001) argues that leadership preparation hasn't kept pace with the changing nature of organisations and the leaders they need, identifying two forms of socialisation that is required by new leaders - professional socialisation for the role in general, which is best done through an appropriate qualification, and organisational socialisation for the specific context where the individual is going to take up their role, best done by the organisation itself. Bush (2018) suggests there are three types of socialisation required - first, professional socialisation, where they learn the role; second, personal socialisation, where they learn to see themselves as a principal rather than a teacher; third, organisational socialisation, where they learn about how to lead a specific school. We shall see below that many of the principals who participated in this study emphasised organisation-specific leadership preparation, suggesting that organisational socialisation was receiving more emphasis than professional socialisation. There is also considerable evidence from a range of contexts that mentoring and coaching by an established principal is a useful supplement to other forms of training (Bush \& Chew, 1999; Hobson \& Sharp, 2005), with Barnett \& O'Mahony (2008) noting that mentoring approaches may differ by cultural setting-for 
example, in more hierarchical cultures there may be more attention to skill development rather than to emotional support.

However, whilst there is an extensive literature on preparation for leadership in national contexts (for example, Bush, 2013; Eacott, 2011; Gunter, Hall \& Bragg, 2013; Gunter \& Ribbins, 2003a, 2003b; Gunter, 2012) there is very little written on preparation for the role of being an international school leader, or the attributes required for successful execution of the role. Roberts \& Mancuso's (2014) work is an exception; they undertake a detailed content analysis of job advertisements for international school Directors with the explicit aim of informing aspiring leaders about the skills they need to develop for such roles. However, the findings focus on styles of leadership and personal attributes sought, rather than specific skill-sets. Another interesting study is by Keung \& Rockinson-Szapkiw (2013), who find a positive correlation between the cultural intelligence of international school leaders and their engagement in transformational leadership. These studies provide some insights into preparation for the role, but deserve to be complemented by asking school leaders directly how they prepared themselves for their leadership positions, both through formal preparation programmes and by understanding the routes they took to taking up their senior leadership role.

Berry and Townsend (2019) argue that the greater independence and autonomy of private schools in the UK compared with their state funded counterparts, produces a larger variability among such schools and 'so any transition to senior leadership could be more complex than an equivalent transition in state (or public) schools' (Berry \& Townsend, 2019 p.4). If this is the case for a group of schools within one nation, then we may expect an even greater variability in a group of heterogeneous schools that exist globally and seemingly held together by their nomenclature in no unitary site. Nevertheless, Bush (2018) believes there is a moral obligation for leadership preparation, however this is problematic within the international school context; it is not clear who the obligation is on, with a whole raft of global employers. 
In summary, this literature review highlights the paucity of empirical data concerning the role of the international school leader, and of the forms of socialisation that are required for effective execution of their roles. These two aspects of international school leadership form the focus of this paper. The study that this article reports on had two research questions:

1. What are the routes to headship, including leadership preparation, followed by international school principals in Malaysia?

2. What are the leadership challenges that face international school principals in Malaysia?

\section{Research Methods}

The research that this article reports upon was a multiple case study. Our focus was on understanding leadership in 12 case-study international schools in Malaysia; although we only report on some of the data from these case-studies in this article, which is focused solely on the interview with the most senior educational leader within each case-study, and does not include other data from within each case-study. Case study as a method has a strength of being contextually in real life situations (Yin, 2014), it provides insightful knowledge from first hand narratives of their experiences and practice. Case studies recognise the complexity of social truths, catch unique data that may be lost in larger studies and provide insights into other similar situations. The real strength of case studies are in 'their attention to the subtlety and complexity of the case in its own right' (Cohen, Manion, \& Morrison, 2018 p.379). However, a disadvantage of case study is that generalisations are problematic (Cohen et al., 2018 p.380). We regard our data as indicative and illuminative, it sheds light onto leadership development and practice in international schools in Malaysia; further work would increase the knowledge in the field.

Twelve principals of international schools in Malaysia were interviewed for this study in 2018. The number of international schools in Malaysia has grown rapidly over the past decade, since the government relaxed regulations that prevented most Malaysians from using international schools in 2012. In September 2018 Malaysia had some 241 international schools, making it the $8^{\text {th }}$ largest provider of such schools globally (ISC Research, 2019). 
The sample of principals interviewed was selected by a combination of opportunistic and purposeful sampling. A professional association of international schools in Malaysia distributed our call for participants, but we also approached many participants directly, being mindful of the need to include a range of schools. Whilst we do not claim that our sample is representative, it includes both schools that primarily served the expatriate population in Kuala Lumpur, and schools that primarily served Malaysians in small towns and cities outside the capital; it includes both for-profit schools and non-profit schools and schools with a range of fees. In this way the range of schools in our sample was deliberate in order to gain rich data. Pseudonyms are employed, with gender preserved, in the analysis below to protect the identity of our participants, and that identifying features of the schools/ individuals concerned have also been removed; the international school world is small and care has to be taken to avoid inadvertently identifying our participants.

None of the participants were Malaysian nationals and were predominately from Western countries such as the UK and the USA. The language of instruction of all the schools was English and whilst the curriculum varied, they were exclusively from Western countries. All the interviews were conducted in English; the mother tongue of all but one participant. All of the schools defined themselves as international schools in their title and the participants all held the highest academic post within the school, frequently called a principal in such schools in Malaysia.

The interviews were recorded and transcribed, the text was analysed using a constant comparison method to generate codes and develop emergent themes (Miles, Huberman, \& Saldana, 2014). The participants indicated the ways in which they had been prepared for their role, and it was evident that their development of skills was a result mainly of serendipity rather than systematic preparation.

\section{Findings and Discussion}


The discussion of the findings is within two broad emergent themes of the routes to headship and the key challenges that international school principals face. Within these two areas further sub themes are also examined

\section{Routes to Headship}

Our twelve participants had taken divergent paths towards international school leadership. Keith, John and Ryan had been principals in their home countries before they moved into international schooling; the remainder of our participants had become principals in the international school world. When they described their path towards headship, a clear plan or active development by others was markedly absent. Rather, several of our participants had simply seen new interesting challenges which had caused them to move incrementally. Philip offered a typical response:

With regards to the progression of becoming a school principal, it was never really my intention to do this. But I was driven by the fact that often I felt that my immediate line manager was something that I could do that or I could do that better.

Similarly, Max explained his job choices over time not in terms of ambition to become a principal, but instead:

It was really opportunities that arise and looking for more challenges and succeed at what I'm trying and give it a go and get a reasonable job and I'm quite pleased with what I've done.

Andrea also described herself as having accidentally fallen into headship, having first got a job in a small school that grew, so that she became a leader of a large group of teachers by being in the right place at the right time. In consequence, they felt that their careers had not been consciously planned; Gordon expressed this path to headship succinctly:

So how did I became an international school principal? Probably, I fell into it.

These participants are therefore in contrast to the Scottish and English heads interviewed by Cowie \& Crawford (2009), who refer to having been talent-spotted early on in their careers. 
Although Gordon had been given guidance by a principal about skill-sets to develop, he was already in a relatively senior position; Claire and Trisha however, both described having been talent-spotted by a school owner:

Basically she came up to me and she said you should go into headship. She said you know your staff better than your senior leadership team do. (Claire)

Our data suggest that international schools lack a strong leadership pipeline that enables the identification of early leadership potential and its cultivation throughout an individual's career. The geographical mobility of individuals in international schools perhaps explains why each school may feel they are not going to benefit from an investment in future leaders; the consequence, however, is to impoverish the leadership capability of the sector in general. This finding emphasises the importance of identifying other ways to support paths to leadership, including effective leadership programmes.

The participants described four main ways in which they had developed their leadership skills: qualifications; role models; mentoring and experience. We shall discuss each of these in turn.

Most of our participants had completed some kind of leadership qualification prior to becoming an international school leader. The qualifications completed included the National Professional Qualification for Headship, an MA Education, a Masters in Educational Leadership, an ILMP (International Leadership and Management Programme) and a Principals' Training Center qualification. Only Andrea, Keith and Trisha had no qualifications in leadership, but Keith had a Masters in Education.

Some participants believed that leadership qualifications were highly useful. Sandra thought they should be a prerequisite to taking up a senior leadership position. Trisha had experienced her lack of qualifications to be a problem and was currently completing one, saying: 
I had no proper course, no one to teach me how to be a principal. And I felt like that was a major disadvantage, compared to the principals of other international schools who had gone through that education to be a leader.

Conversely, others expressed reservations about the utility of such qualifications:

I don't believe that you can train to be a principal...I think it's all about the characteristics, either you have them or you don't. (Philip)

I don't think you learn how to be a leader by doing degrees, quite frankly...I don't necessarily think leaders are born either; I think you can grow into leadership. (John)

In other words, it is clear that several participants had reservations about the use they had derived from completing qualifications that were not rooted in the skills and knowledge needed by leaders in international schools. This echoes Harris, Jones \& Adams' (2016) finding that importing leadership qualifications from different cultural contexts can be highly problematic, and emphasises the need for international school specific leadership preparation. However, even if such qualifications were, in Gunter et al's (2013) terms, functional (descriptive or normative), their utility could be called into question for this international school leadership. It is clear that several of our sample desire utility but others are dismissive.

Some of the participants mentioned various role models during their careers, who had influenced their leadership practices. For example, Philip said:

Role models...I'm very much a person who looks up towards...I like to look how people do things. And I've had the real privilege of watching someone lead a school extremely well and I've had the... I class it as a privilege to watch someone run a school pretty badly.

However, the majority of our participants made no allusion to a role model who had inspired them, by providing either a positive or a negative example. 
Crawford \& Earley (2011) discuss how mentoring can be very useful to trainee heads, and many of the participants described having a mentor whilst performing a leadership role, either currently or in a previous position. For example, when Andrea first became a head of section, her school principal offered considerable support:

The head teacher and myself were both fairly new into that type of role. And it was a really special time because every morning we would meet have a cup of tea and plan the day...So I was very lucky... I had a daily mentor.

Similarly, Trisha spoke about the support she got from the previous principal:

She always had my back. She always, always said, 'What do you think?' The first year was - everyday l'd be sitting there '[Name of principal], what do I do?', '[Name of principal], what do I do?' And then slowly she said, 'You've got to stop asking me.'

Some of our participants led a school that was owned by a corporation which owned several other schools, either within Malaysia or internationally. They spoke about finding it useful to get support from the other principals and from the head of the corporation. Other participants spoke about their school's owners having corporate/ leadership experience that they were able to draw on when they found it helpful. Mentoring was thereby one of the two most important forms of preparation mentioned by participants (Bush \& Chew, 1999; Hobson \& Sharp, 2005; Barnett \& O’Mahony, 2008).

Finally, many participants argued that learning from experience was essential, indeed this was often claimed to be the most important form of preparation. Most of them had few opportunities for formal feedback from anyone in their organisation, and argued that applying the skill of self-reflection was essential. John averred:

I still make mistakes and have to learn from those...I think effectiveness comes with passing of time and learning from those mistakes, and adjusting to the changes that you have faced, in terms with the context that you are operating. It's not rocket science. 
It would be of interest in further work to look at the connection between temporary posts of international school principals and the nature of their leadership. Does leadership become a functional perspective ('get the will of the owner done') or a role that has independent critical thought? It may well be that their agency is reduced by their very transience.

The evidence from our sample suggests that preparation for aspiring leaders is rarely emphasised in international schools. Participants stressed instead the importance of learning the skill of self-reflection, and being able to learn from mistakes. Alongside this, there was discussion of the importance of mentoring to their journey towards leadership. As this mentoring was usually provided by someone within their organisation (a more senior leader, a trustee or owner), there is a risk that of the forms of socialisation mentioned by Crow (2001) and Bush (2018), organisational socialisation, is receiving more emphasis than professional or personal socialisation; in many cases, mentors were not educational professionals themselves, so that socialisation into a profit-driven organisation was receiving more attention than professional allegiance.

Key Challenges of International School Leadership

After ascertaining their routes to headship, we questioned the principals about the key challenges of their role. Several participants spoke to us about features of the role that they felt were significantly different from being leaders of schools in national contexts, although only three participants had direct experience of leading a school in a national context. In this section, we shall discuss each of the key challenges in turn.

Loneliness

The first challenge for many participants was dealing with the loneliness of being the principal of an international school. They felt that this was more acute than the loneliness of the role in national settings. The institution itself is more isolated, as it is 'detached' from the host nation schools around it, following a different curriculum and typically operating in 
a different language. The school leader is likely to lack networks away from the school. In other words, whilst loneliness is common to all headships, it may be accentuated in the international environment where the principal has arrived in a new country where s/he lacks established networks, often lives close to the school, and finds that their social life overlaps with school life - what Caffyn (2010) refers to as a 'psychic prison mentality' (p. 328) of international schools.

Networking skills become extra salient in this situation. A number of the principals referred to various formal organisations of international schools in Malaysia and across South-East Asia. Max explained why he had made participating in networks of international schools a priority:

It's a very lonely place as an international school. You need to get you networks, you need to make sure what you are doing.

It was noticeable that nearly all our participants advised newcomers to get involved with international school networks, in part to counteract the loneliness. Although these schools were ostensibly competitors with one another, Claire particularly pointed this out, several of the principals had stories of other headteachers reaching out to offer support when they first arrived in the country. Sandra found this very useful; working 14 hours a day several days a week and answering emails every day throughout the school holidays, she had no time to construct an independent social life upon arriving in a new country, particularly as she had arrived with no family. An exception to this was Keith, who was not aware that any associations of principals existed in Malaysia. He was principal of a small school that was not connected to these organisations, and relatively new to the country. The principals of schools that were in 'chains' or groups benefitted from networking within the group, the schools being frequently in different geographical locations and not in direct competition.

This loneliness also manifested itself in that all our participants developed at least one confidante, a 'go to' person for confidential professional advice. Some of the schools involved in this study were owned by corporations with more than one school. Their leaders found talking to other principals in the corporation, whether in Malaysia or beyond, another 
helpful source of support. It was therefore clear that the ability to construct and use networks effectively was particularly important to the execution of these international school principals' roles. In the cases where the school had a singular owner, such as Ryan and Trisha, this confidante was another member of the owner's family, who was also an employee, who they trusted.

Transience

Echoing the work of Gardner-McTaggart (2018), the transient nature of international schools featured in the interviews as a key challenge faced by the international school leader. Transience was threefold; turnover and insecurity of students, staff and the principals themselves. In some schools, there was a large turnover of children, although in schools with a large proportion of local (Malaysian) students this was less of an issue. For example, Martin's school had several children of Foreign Service officials, who left every two years on another assignment, while Ryan had a $20 \%$ turnover in the student population each year as expatriate families departed. As in the international schools studied by Lee, Hallinger \& Walker (2011), short-term contracts were the norm in all of these schools, both of teaching staff and of the principals themselves. For example, Claire was on a 2-year contract and felt that this was too short a period to impact on the culture of a school.

The principals developed strategies to cope with this transience. Some sought a balance in their student bodies and on their staff to protect the school against future fluctuations in specific populations, for example staff with families were specifically sought as they were thought likely to stay longer than single teachers. One specific issue in relation to transient staff was safeguarding, and some principals reported developing procedures to check the backgrounds of teachers coming from a range of countries, some without detailed background checks on adults working with children. Here, principal networks were important, which enabled principals informally to warn one another about teachers whose background may be a matter of concern. 
On the other hand, some principals reported that transience was not a feature of their schools. Gordon's school predominantly served host country national students, and also had a high proportion of Malaysian teachers:

A lot of our students will spend 11-12 years at the school. A lot of the teachers have been here for 1520 years.

Although he was on a limited two year contract, it had been repeatedly renewed over a number of years and he was deliberately attempting to build greater stability by employing more Malaysian teaching staff with less reliance on expatriates. With over twothirds of the students being Malaysian, this was clearly a 'local' international school. He did not compute exact figures for longevity, but the school had a low transient workforce and student body. One wonders if this will become a characteristic of such schools.

\section{Cultural Differences}

All of the principals discussed the cultural challenges they faced in leading an international school and the skills they had developed to meet these. This echoes Keung \& RockinsonSzapkiw's (2013) exploration of the importance of cultural intelligence to international school leaders.

Max stressed the importance of a principal quickly gaining an understanding of the local culture:

Just to get to know the people and the culture as quickly as possible. And understand that it's going to be different than other country that you have been in because losing face is important and not losing face is important. How you behave and what you say and how you say it.

Cultural differences affected diverse relationships with students, parents, teachers and school owners. For example, Philip had experienced cultural differences in how parents 
viewed the home-school relationship, echoing Blandford \& Shaw's (2001) assertion that high but varied parental expectations are a major challenge for international school leaders:

Lots of different nationalities of parents, and we've all got a different view of whether they should have an input in schools or whether they shouldn't and there are some nationalities that you shouldn't question the leader and some who very much want to.

In their study of the use of critical friends in schools, Swaffield \& MacBeath (2005) point out that the power distance that applies in a particular culture may alter the dynamics of this relationship, noting that in some cultures it is not acceptable for a more senior person to admit areas of ignorance. These cultural differences in how authority is expressed were played out in the current study through relationships with both owners and staff. For instance, Keith had learnt that the owner of his school didn't like to 'lose face' by being contradicted publicly. Claire had been surprised by some of the assumptions made by the owners of her current school:

They are Chinese [Malaysians]. They've got some very funny ideas about finance, the school budgets, and not disclosing information about numbers.

In addition, Ryan referred to cultural differences in how support staff executed their responsibilities; he felt that the local culture encouraged people to be reactive rather than proactive, so that his oversight needed to be more proactive.

The principals described the necessity for clear communication with their staff and parent body, and being explicit about assumptions that might be taken for granted in another cultural setting. For instance, John said:

The Chinese [Malaysians] have been brought up in an education system that is very traditional, very demanding and very focused, and that's not the way we do things in teaching and learning anymore. There are other ways to skin the cat where the kids can actually enjoy the process of learning. And so it's being proactive in getting the parents in and explaining the sorts of strategies that schools employ nowadays. 
Teacher training was central to school leaders working with a culturally mixed teaching staff. Max had a culturally mixed teaching body, and this necessitated offering clear teacher training on approaches used commonly in English schools to deliver the English curriculum.

Most of the principals expressed an openness to the different cultural experiences involved in leading an international school.

\section{Governance}

Benson's (2011) large-scale study of administrator turnover in international schools found that the most common reason for an administrator leaving was the school board, specifically either changes in the board composition or micro-managing by the board. Similarly, our study identified managing constructive relationships for effective governance as a central element of the international school principal's role. In most national contexts of school leadership, there are clear structures for governance (Hayden \& Thomas, 2008); whilst there may be differences between private and public schools, there are usually established parameters and regulatory frameworks that are frequently legally binding. Whilst recognising that governance models used in many national systems have become increasingly diverse in recent years, they still typically adhere to these norms, whereas an international school may not have a board at all, with a principal talking directly to a single owner (Hayden \& Thomas, 2008). By contrast, the principals reported highly diverse systems of governance in international schools (Blandford \& Shaw, 2001; James \& Sheppard, 2014) and having to negotiate their own role carefully. For example, Philip led a for-profit school whereas Max's school was a charity; yet, both placed a similar emphasis on the amount of trust the owners placed in them. We suggest that the range of governance models in international schools is a fruitful area for further research.

The scope of duties that fell under headship varied between organisations. Some of the principals compared themselves to a CEO, whereas Keith reported that the owner acted as the CEO in his school. Andrea had found her role as a principal changing substantially as the school had been bought and sold by various owners; under some owners it felt like she was working for a business, whereas under others it felt more like she worked for a school. In 
John's previous headship, the owners had been non-educationalists, and that had caused problems as they had made decisions that caused friction with parents. However, his present owners specialised in education, and he felt they had a useful expertise to offer. Alistair led a parent-governed school. He had spent a lot of time developing the governing body, making sure that they were trained, that the school was implementing best governance practice and that the governors' contributions to the school were optimised.

\section{Business Elements}

Several of the principals saw their role as closer to being a CEO than a traditional headteacher. In consequence, they had had to acquire a range of business-related skills, such as marketing and finance; Claire described her decision to dismiss several people, including someone suffering from mental illness, as 'normal' in a school start-up. This did not only apply to headteachers working in for-profit schools, but was particularly acute in some of the for-profit institutions. Alistair worked for a not-for-profit school, but nevertheless compared himself to a CEO:

The very nature of leading of school, as compared to what it was 10-20 years ago, is very different now. Nowadays you are a CEO...You are expected to deal with all of the things that anyone running a business organisation would need to do.

He explained that most of his time was spent in meetings overseeing both the academic and non-academic leadership team; he had exerted considerable energy in overseeing major infrastructural changes. Martin reported that he had ensured that those in charge of admissions and marketing reported directly to him rather than to the Head of Operations because:

Admissions and marketing are seen as the driving force of the school. We've got to get that right.

He felt this element of the role was the biggest single change from his prior role, a head of primary section in the same school. The principals varied in the extent to which they 
thought that international school principals needed to actively engage with the business side of the role. John stressed the variability of the role:

And having worked at four international schools, all of them have been quite different, where some want you to be at the grassroots level in the classrooms and others want you to be fulfilling more of the CEO type, more remote just simply by the pressure of paperwork and planning and strategy.

The principals who worked in for-profit schools all sought either to emphasise the positives of this environment, or to claim that they protected educational aspects from being encroached on by the business side. For example, Martin pointed out that being part of a larger business had enabled the school to borrow money when it wasn't making a profit, but said his main advice for a new international school principal would be:

It's really important to stick to your educational principles, as in your pedagogy and the way that you think education should be, but still have in mind that you are working for a business.

All the principals were conscious of their school's market position. Gordon argued that the exponential expansion of international schools in Malaysia was one of his biggest challenges, especially against a background of problems in the oil and gas sector, traditionally one of the strengths of the Malaysian economy. As a result, international schools were poaching students, and sometimes teachers, from one another. Gordon warned:

We're going to go through a period where people are being very cut-throat about fees, about scholarships, just to try and keep afloat. I think there's going to be closures, which will shake people's confidence in the system.

He felt that the competitive and business-oriented aspects of international school headship were going to become more prominent.

Managing School Composition 
There were three major ways in which principals reported actively managing the composition of the school community: the cultural make-up of the student and staffing bodies; language issues; and special educational needs. While Gardner-McTaggart (2018) sees international school leaders as focused on maintaining student numbers, our data suggest that who makes up the numbers is equally important to these leaders.

Managing the cultural composition of either the student body and/ or the teaching staff featured heavily in the interviews, with many of the principals reporting that demographic decisions were an important aspect of their role. Historically, the Malaysian government had restricted the number of Malaysians who could attend international schools; since these restrictions had been relaxed in 2012, some schools had imposed restrictions of their own. For example, Andrea limited the percentage of Malaysian students, stating: "We don't go above 40\%." In addition, she required that all teachers (apart from language teachers) be British trained and experienced in teaching the English curriculum, although they did not have to be British passport holders. She justified these measures as necessary in order to be a "true" British school - a feature of the school's marketing.

John said that managing to maintain a balance between the different cultures in the school was his biggest challenge, explaining that he didn't want children who shared a first language other than English to group together and form "cliques":

The point is that we are not too heavily weighted with one particular nationality to the detriment of the others.

Language issues were also mentioned by Martin, who reported having restricted the number of students from China in order to protect the international features of the school and to ensure that the students used English language in their friendship groups. Sandra said that language did not feature in her admissions decisions at primary level, but that no single nationality was permitted to exceed $25 \%$ of the student body, so that the internationalism of the school was maintained. The reasons given for managing the cultural composition of the staffing body differed. Both Max and Martin reported that their governors had set caps on the number of expatriate teachers they could recruit for financial 
reasons - as expatriate staff were paid more than local staff. By contrast, in Sandra's school, the ethnicity/ nationality of a teacher was considered irrelevant during recruitment, although she acknowledged that there was a predominance of Western staff simply because of their familiarity with the curriculum and relevant teaching methodologies. However, Claire felt that a more insidious reason had affected recruitment policy in her school before she had arrived, claiming "international schools want white faces" for marketing reasons, adding "it's just overwhelming with selling whiteness." She tried to recruit a range of expatriate teachers from different backgrounds, and feature them all on the school's website.

Special educational needs provision was frequently referred to during the interviews. Several principals reported that they aimed to be inclusive, but that they imposed various restrictions on full inclusion. This was justified in terms of needing to be sure that they could meet an individual's needs, but heads also admitted struggling to reconcile their belief in inclusion with the business side of their school. Martin explained that he had admitted many students with special needs:

But what it does for us as a school is, it also puts a name for the school out there as being The Special Needs School. So, there are a lot of schools out there that are very exclusive. That actually sells themselves on 'we don't have any special needs at our school'.

Trisha was unabashed by her selection decisions; she was clear that her school did not accept students with special needs, and also refused to admit one boy for wearing an earring and another for having long hair in a ponytail "because we pride ourselves in being a very traditional school." By contrast, Ryan thought that being selective (about language proficiency and SEN) sat uncomfortably with his previous role as a principal in his home country:

That's the hard part. As a public educator, it's a different role. Its business. That's probably the biggest personal challenge. Not to just fling your arms open and take them all in. 
The notion that the job of the principal is to actively manage the school community in terms of ethnicity, nationality, first language and special educational needs is in sharp contrast to how such practices would be viewed in many Western settings - and indeed would run counter to equality legislation in some countries. It is notable that these schools frequently had admissions policies that were different to what clearly was occurring operationally. Yet, all of these principals were trying to grapple with these concerns in a reflective manner to improve education in their institutions. This clearly demonstrates how the issues to be discussed in principal preparation for international schools can be expected to differ markedly from those for leadership preparation in national settings.

We have identified six key features of the international school principal's role that our participants identified as differing from school leadership in national contexts. However, finally, it is important to draw attention to key aspects of a principal's role in many other contexts that were conspicuously absent from these interviews. None of the principals mentioned behaviour management as taking up much of their time, for example; indeed, Andrea expressed a concern that so many children were over-achieving in her school that children were made to feel inadequate who would have been considered high-flyers in other contexts. Another salient absence was that none of the principals discussed challenges in stimulating parental involvement; indeed, many of them had found the need to demarcate roles for parents to prevent what they saw as parents wishing to overstep their role. In summary, while international school leaders report a range of issues that are specific to international school leadership, there are equally a number of aspects of headship in national contexts that barely feature in international schools.

\section{Conclusion}

This paper has focused on the contrasts between international school headship and school leadership in national contexts. We are acutely aware of the small size of our sample and the subsequent tentative nature of our conclusions; however, these findings merit further work in additional contexts. We have seen that individuals take diverse routes to leadership in international schools and that these institutions lack a clear leadership pipeline. We have 
noted that varied forms of leadership preparation were followed by these individuals, and that some felt that their preparation had been insufficient. Building on the work of the few previous researchers who have examined this area (Calnin et al, 2018; Gardner-McTaggart, 2018; Blandford \& Shaw, 2001; Benson, 2011; Keller, 2015; Lee, Hallinger \& Walker, 2011; Keung \& Rockinson-Szapkiw, 2013), we have identified key challenges of the role of the international school principal: loneliness; transience; cultural differences; governance; business elements; and managing school composition.

The heads discussed their sense of isolation and the measures that they took in an attempt to mitigate a sense of loneliness in their decision-making. The schools in our sample differed in their level of transient staff and students, some principals saw it as challenge to bring more order and less change; in particular where the student population had a sizable proportion of Malaysian national children then there was greater stability. All our participants referred to the nature of dealing with cultural differences in Malaysia between owners, governors, staff and parents, and the navigation of these cultural differences was a challenge for our principals. There was a range of governance models in our sample, from single owners to parental groups to a more corporate multi school organisation. This created different challenges ranging from owners being on school site daily to those where owners were transnational. There was a particular focus around the student roll and its financial consequences. The discourse within the interviews was often on the language of business: profit margins; price of the product (fees); competition and marketing. Finally, a key element of the principals' role also appeared to be managing the composition of the student population in terms of special educational needs and ethnic groups. It appears there are also distinct differences of leadership challenges in those schools that are 'international' international schools and 'local' national schools; again, this area needs further research.

Our research into the different challenges involved in headship of international schools means that there is a need for further research into leadership preparation courses for international school principals. However, there is no unitary 'site' for the leadership preparation of international school principals; this creates a vacuum in terms of leading the leadership preparation of such staff. Moreover, we postulate that such preparation may be 
difficult as the challenges they face may well differ globally and further work needs to be carried in other locations in order to contribute to the field. The leadership preparation of our sample was frequently inadvertent, and their routes to leadership in international schools varied. The challenges that our participants faced varied and the wide range of types of international school will create inherent problems in creating a unified programme that principals may find useful.

In this article we have examined the challenges of an international school principal's role in the specific context of Malaysia; the contextual variations bringing different leadership challenges within one host nation were significant. However, we should finish by emphasising some of the commonalities. Philip described the driving principle behind every decision he made:

Don't make decisions based on what's right for you and what's right for the teachers, and what's right for the parents, always based your decisions on what's right for the children and then I still believe that idea that you can then go home and sleep.

This is what underpins effective school leadership everywhere.

\section{References}

Barnett, B. G., \& O'Mahony, G. R. (2008). Mentoring and coaching programs for the professional development of school leaders. International handbook on the preparation and development of school leaders, 232-262.

Benson, J. (2011) An investigation of chief administrator turnover in international schools. Journal of Research in International Education, 10(1), 87-103.

Berry, J., \& Townsend, A. (2019). Peter's Transition to Headship: What Can We Learn From His Experience About How to Prepare to Make the Transition From Assistant Principal, or Deputy, to Principal or Head Teacher? Journal of Cases in Educational Leadership, 1555458919848131. 
Blandford, S. and Shaw, M. (2001) The nature of international school

leadership. In: Blandford, S. and Shaw, M., eds. Managing International Schools. London: Routledge Falmer, pp. 9-28.

Bunnell, T., Fertig, M., \& James, C. (2016). What is international about International Schools? An institutional legitimacy perspective. Oxford Review of Education, 42(4), 408-423.

Bunnell, T., Fertig, M., \& James, C. (2017). Establishing the legitimacy of a school's claim to be "International": the provision of an international curriculum as the institutional primary task. Educational Review, 69(3), 303-317.

Bush, T. (2013). Preparing Headteachers in England: Professional Certification, not Academic Learning. Educational Management Administration \& Leadership, 41(4), 453-465.

Bush, T. (2016). Preparation for school principals: Rationale and practice. Educational Management Administration \& Leadership, 44(4), 537-539

Bush, T. (2018). Preparation and induction for school principals: Global perspectives. Management in Education, 32(2), 66-71.

Bush, T., \& Chew, J. (1999). Developing human capital: training and mentoring for principals. Compare: A Journal of Comparative and International Education, 29(1), 41-52.

Caffyn, R. (2010). 'We Are in Transylvania, and Transylvania Is Not England': Location as a Significant Factor in International School Micropolitics. Educational Management Administration \& Leadership, 38(3), 321-34.

Calnin, G., Waterson, M., Richards, S., \& Fisher, D. (2018). Developing Leaders for International Baccalaureate World Schools. Journal of Research in International Education, 17(2), 99-115.

Cohen, L., Manion, L., \& Morrison, K. (2018). Research methods in education. Abingdon Routledge.

Cowie, M., \& Crawford, M. (2009). Headteacher preparation programmes in England and Scotland: do they make a difference for the first-year head? School leadership and Management, 29(1), 5-21.

Crawford, M., \& Earley, P. (2011). Personalised leadership development? Lessons from the pilot NPQH in England. Educational Review, 63(1), 105-118.

Crow, G. M. (2001). School leader preparation: A short review of the knowledge base. Nottingham, United Kingdom: National College for School Leadership., 25, 2006. 
Eacott, S. (2011). Preparing 'educational' leaders in managerialist times: an Australian story. Journal of educational administration and history, 43(1), 43-59.

Gardner-McTaggart, A. (2016). International elite, or global citizens? Equity, distinction and power: the International Baccalaureate and the rise of the South. Globalisation, societies and education, 14(1), 1-29.

Gardner-McTaggart, A. (2018). International schools: leadership reviewed. Journal of Research in International Education, 17(2), 148-163.

Gunter, H. M. (2012). Leadership and education reform: Bristol: The Policy Press

Gunter, H., Hall, D., \& Bragg, J. (2013). Distributed leadership: A study in knowledge production. Educational Management Administration \& Leadership, 41(5), 555-580.

Gunter, H., \& Ribbins, P. (2003a). Challenging orthodoxy in school leadership studies: knowers, knowing and knowledge? School Leadership \& Management, 23(2), 129147.

Gunter, H., \& Ribbins, P. (2003b). The field of educational leadership: studying maps and mapping studies. British Journal of Educational Studies, 51(3), 254-281.

Gurr, D. (2015). A model of successful school leadership from the international successful school principalship project. Societies, 5(1), 136-150.

Hallinger, P., \& Chen, J. (2015). Review of research on educational leadership and management in Asia: A comparative analysis of research topics and methods, 19952012. Educational Management Administration \& Leadership, 43(1), 5-27.

Harris, A., Jones, M., \& Adams, D. (2016). Qualified to lead? A comparative, contextual and cultural view of educational policy borrowing. Educational Research, 58(2), 166-178.

Hayden, M. \& Thompson, J.J. (2008). International Schools: growth and influence. Paris: United Nations Educational, Scientific and Cultural Organisation.

Hayden, M. (2011). Transnational spaces of education: The growth of the international school sector. Globalisation, societies and education, 9(2), 211-224.

Hobson, A. J., \& Sharp, C. (2005). Head to head: a systematic review of the research evidence on mentoring new head teachers. School Leadership \& Management, 25(1), 25-42. Hofstede, G. (2011). Dimensionalizing cultures: The Hofstede model in context. Online readings in psychology and culture, 2(1), article 8, pp.3-26. 
IBO (2012). Empowering Leaders in International Education: IB leadership certificates.

Available at: https://ibo.org/globalassets/professional-development/ib-leadershipbrochure-2017-en-2.pdf (accessed 9th December 2018).

ISC Research (2019). https://www.iscresearch.com Accessed 7 $7^{\text {th }}$ March 2019.

James, C., \& Sheppard, P. (2014). The governing of international schools: The implications of ownership and profit motive. School Leadership \& Management, 34(1), 2-20.

Keller, D. (2015). Leadership of international schools: Understanding and managing dualities. Educational Management Administration \& Leadership, 43(6), 900-917.

Lee, M., Hallinger, P., \& Walker, A. (2012). Leadership challenges in international schools in the Asia Pacific region: evidence from programme implementation of the International Baccalaureate. International Journal of Leadership in Education, 15(3), 289-310.

Keung, K.E., \& Rockinson-Szapkiw, J.A. (2013). The relationship between transformational leadership and cultural intelligence: A study of international school leaders. Journal of Educational Administration, 51(6), 836-854.

Leithwood, K., Day, C., Sammons, P., Harris, A., \& Hopkins, D. (2006). Seven Strong Claims about Successful School Leadership (Nottingham, NCSL/DfES). Available on-line at: http://www. ncsl. org. uk/media/ECB/97/seven-claims-to-success. pdf.

Miles, M. B., Huberman, A. M., \& Saldana, J. (2014). Qualitative data analysis: A methods sourcebook. London Sage.

Principals' Training Center (2018). Standards for the International School Principal. Available at:

https://static1.squarespace.com/static/57c4731c893fc047731cea43/t/57ffe3502009 9e8c38f8c65e/1476387666247/Standards+for+Principals+revised+arpil2016.pdf (accessed $9^{\text {th }}$ December 2018).

Roberts, L., \& Mancuso, S. V. (2014). What kind of international school leaders are in demand around the world? A test of differences by region and stability over time. Journal of Research in International Education, 13(2), 91-105.

Scandura, T., \& Dorfman, P. (2004). Leadership research in an international and crosscultural context. The Leadership Quarterly, 15(2), 277-307.

Swaffield, S., \& MacBeath, J. (2005). School self-evaluation and the role of a critical friend. Cambridge Journal of Education, 35(2), 239-252. 
Yin, R. K. (2014). Case study research: Design and methods. London: Sage publications. 